\title{
Current Status of Antimicrobial Resistance in Taiwan
}

\author{
Po-Ren Hsueh, ${ }^{*}$ Cheng-Yi Liu, $†$ and Kwen-Tay Luh*
}

\begin{abstract}
While some trends in antimicrobial resistance rates are universal, others appear to be unique for specific regions. In Taiwan, the strikingly high prevalence of resistance to macrolides and streptogramin in clinical isolates of gram-positive bacteria correlates with the widespread use of these agents in the medical and farming communities, respectively. The relatively low rate of enterococci that are resistant to glycopeptide does not parallel the high use of glycopeptides and extended-spectrum beta-lactams in hospitals. The evolving problem of extended-spectrum beta-lactamase-producing Escherichia coli and Klebsiella pneumoniae isolates is substantial, and some unique enzymes have been found. Recently, some gram-negative bacteria (e.g., Pseudomonas aeruginosa and Acinetobacter baumannii) that are resistant to all available antimicrobial agents including carbapenems have emerged.
\end{abstract}

A ntimicrobial resistance has become a major health problem worldwide, affecting every country to some degree. It is an inevitable consequence of the inappropriate use of antibiotics in humans and animals. In Europe and North America, methicillin-resistant Staphylococcus aureus (MRSA), penicillin-nonsusceptible Streptococcus pneumoniae (PNSSP), vancomycin-resistant enterococci (VRE), and extended-spectrum beta-lactamase (ESBL)-producing Enterobacteriaceae have emerged and spread into communities and hospitals. In Taiwan, the widespread use of antimicrobial agents in primary care clinics and animal husbandry has allowed the rapid emergence of resistant bacteria. During the last 2 decades, many antimicrobial agents-such as extended-spectrum cephalosporins, carbapenems, fluoroquinolones, and aminoglycosides-have been introduced and empirically used as first-line drugs to treat these resistant bacteria $(1,2)$. This has further accelerated the development and dissemination of drug-resistant bacteria. Previous studies in Taiwan have clearly demonstrated the remarkably high prevalence of some critically resistant bacteria, such as MRSA, PNSSP, and macrolideresistant streptococci $(1,2)$. In addition, several multidrugresistant bacteria, including ones resistant to carbapenems and fluoroquinolones and pan-drug-resistant gram-negative bacilli, have been isolated from different hospitals (3-6).

\section{Approval of Antibiotics}

Table 1 shows the years that selected antibiotics were approved in Taiwan. These antibiotics are now widely used to treat various infections, including community-acquired and nosocomial infections. Until now, two gylcopeptides (vancomycin and teicoplanin), two carbapenems (imipenem and meropenem), four macrolides (erythromycin, roxithromycin, clarithromycin, and azithromycin), and six quinolones (nalidixic acid, norfloxacin, ofloxacin, lomefloxacin, ciprofloxacin, and levofloxacin) have been available for clinical use in Tai-

*National Taiwan University Hospital, National Taiwan University College of Medicine, Taipei, Taiwan; †and Taipei Veterans General Hospital and National Yang-Ming University, Taipei, Taiwan wan. Most of these drugs were also readily available at drugstores without prescription before 1995 .

\section{Drug-Resistant Bacteria}

The following drug-resistance data were collected from a nationwide resistance survey (Surveillance from Multicenter Antimicrobial Resistance in Taiwan) of clinical isolates (including those recovered from hospitals and outpatients) from 12 major hospitals as well as isolates causing nosocomial infections from National Taiwan University Hospital (NTUH) in 2000 in Taiwan. These hospitals are located in different parts of the country. The number of beds in these hospitals ranged from 800 to 3,200. All these data were derived by using the disk-diffusion method (7).

Some dilution antimicrobial susceptibility and epidemiology studies, including $\geq 100$ strains published in English-language journals from January 1995 through 2001, were also included. Rather than provide a comprehensive review of all resistance problems in Taiwan, our aim was to point out some of the more critical resistance problems threatening the treatment of infections caused by Staphylococcus species, S. pyogenes, Streptococcus pneumoniae, Enterococcus species, and

\begin{tabular}{lc}
\hline Table 1. Year of approval of selected antimicrobial agents in Taiwan \\
\hline Antimicrobial agent & Year of approval \\
\hline Erythromycin & 1968 \\
Oxacillin & 1970 \\
Gentamicin & 1981 \\
Cefotaxime & 1983 \\
Amikacin & 1986 \\
Ceftazidime & 1988 \\
Imipenem & 1988 \\
Vancomycin & 1983 \\
Ciprofloxacin & 1990 \\
Cefepime & 1997 \\
\hline
\end{tabular}


Mycobacterium tuberculosis among the gram-positive pathogens, and Haemophilus influenzae, Escherichia coli, Klebsiella pneumoniae, Enterobacter species, Salmonella species, Campylobacter species, Pseudomonas aeruginosa, and Acinetobacter baumannii among the gram-negative pathogens. Resistance rates included in this review reflect both intermediate and fully resistant populations. Table 2 summarizes the prevalence of antimicrobial resistance among clinical isolates (12 hospitals, including NTUH) and nosocomial isolates (from NTUH only) of some selected bacterial species. The ranges in numbers of clinical isolates of select bacteria (Table 2) recovered from these hospitals were as follows: Staphylococcus aureus, 1,889 to 7,516 isolates; beta-hemolytic streptococci, 335 to 1,$102 ;$ S. pneumoniae, 138 to 461 ; enterococci, 509 to 3,$676 ; H$. influenzae, 427 to $602 ; E$. coli, 1,734 to 9,$553 ; K$. pneumoniae, 950 to 3,226; E. cloacae, 427 to 1,426; nontyphoid Salmonella, 94 to 626; P. aeruginosa, 1,741 to 4,896; and A. baumannii, 896 to 2,434 .

\section{Gram-Positive Bacteria}

\section{MRSA}

MRSA was first documented in Taiwan in the early 1980s (8). Since then, there has been a remarkable increase in prevalence of MRSA in nosocomial infections (from 26.7\% in 1990 to $75 \%$ to $84 \%$ in $1998-2000$ ) (9). Several dominant clones have been documented in hospitals (9). The prevalence of MRSA in community-acquired infections remains unclear, although the incidence of MRSA among patients of outpatient departments is estimated to be $40 \%$ (1). Data from a survey of $>5,000$ clinical isolates of $S$. aureus at the NTUH from January 1999 to June 2001 using brain-heart-infusion agar plus 4 $\mathrm{mg} / \mathrm{L}$ of vancomycin showed results negative for vancomycinintermediate or -resistant strains.

\section{PNSSP and Multidrug-Resistant Streptococcus pneumoniae (MDRSP)}

The overall prevalence of clinical isolates of PNSSP in $1999-2000$ was $60 \%$ to $80 \%$, including $20 \%$ to $30 \%$ penicillinintermediate and $40 \%$ to $50 \%$ penicillin-resistant strains (1016). This prevalence of PNSSP was slightly lower than that in Korea and higher than that in most other geographic areas $(15,16)$. All PNSSP were resistant to multiple antibiotics $(13,16)$. This resistance was higher among nasopharyngeal isolates from children (12). Approximately $60 \%$ of the PNSSP isolates were also not susceptible to extended-spectrum cephalosporins and carbapenems (13). Most of these PNSSP belong to serotypes $23 \mathrm{~F}, 19 \mathrm{~F}, 6 \mathrm{~B}$, and $14(13,15)$. Wide dissemination of multiple high-level penicillin-, extended-spectrum cephalosporin-, and macrolide-resistant clones as well as the Spain $23 \mathrm{~F}$ clone contributes to the high rates of resistance to these drugs in clinical isolates of $S$. pneumoniae $(14,17)$. Only one clinical isolate was reported to be resistant to fluoroquinolones (18).
Table 2. Prevalence of antimicrobial resistance in selected bacteria (all clinical isolates) isolated from 12 major hospitals, including National Taiwan University Hospital (NTUH), in Taiwan in 2000 and in all clinical isolates and isolates causing nosocomial infections from NTUH in $2000^{\mathrm{a}}$

\begin{tabular}{|c|c|c|}
\hline \multirow[b]{2}{*}{ Resistant pathogen } & \multicolumn{2}{|c|}{$\%$ of isolates } \\
\hline & $\begin{array}{c}2,000 \\
\text { (12 hospitals) } \\
\text { (clinical) }\end{array}$ & $\begin{array}{c}2,000 \\
\text { (NTUH) } \\
\text { (clinical/nosoco- } \\
\text { mial) }\end{array}$ \\
\hline $\begin{array}{l}\text { Methicillin-resistant Staphylo- } \\
\text { coccus aureus }\end{array}$ & $53-83$ & $65 / 74$ \\
\hline $\begin{array}{l}\text { Erythromycin-resistant beta- } \\
\text { hemolytic streptococci }\end{array}$ & $30-51$ & $34 /-$ \\
\hline $\begin{array}{l}\text { Penicillin-nonsusceptible Strep- } \\
\text { tococcus pneumoniae }\end{array}$ & $60-84$ & $77 /-$ \\
\hline $\begin{array}{l}\text { Erythromycin-resistant S. pneu- } \\
\text { moniae }\end{array}$ & $67-100$ & 89/- \\
\hline $\begin{array}{l}\text { Gentamicin-resistant (high- } \\
\text { level) enterococci }\end{array}$ & $36-54$ & $48 / 54$ \\
\hline $\begin{array}{l}\text { Vancomycin-resistant entero- } \\
\text { cocci }\end{array}$ & $1-3$ & $3 / 2$ \\
\hline $\begin{array}{l}\text { Ampicillin-resistant } H \text {. influen- } \\
\text { zae }\end{array}$ & $45-73$ & $61 /-$ \\
\hline $\begin{array}{l}\text { Cefotaxime-resistant Escheri- } \\
\text { chia coli }\end{array}$ & $5-19$ & $12 / 19$ \\
\hline Ciprofloxacin-resistant $E$. coli & $11-33$ & $20 / 29$ \\
\hline $\begin{array}{l}\text { Cefotaxime-resistant Kleb- } \\
\text { siella pneumoniae }\end{array}$ & $4-34$ & $9 / 18$ \\
\hline $\begin{array}{l}\text { Ciprofloxacin-resistant } K \text {. } \\
\text { pneumoniae }\end{array}$ & $5-33$ & $9 / 16$ \\
\hline Cefotaxime-resistant E. cloacae & $36-68$ & $45 / 49$ \\
\hline $\begin{array}{l}\text { Ampicillin-resistant non- } \\
\text { typhoid Salmonella }\end{array}$ & $44-69$ & $56 /-$ \\
\hline $\begin{array}{l}\text { Cefotaxime-resistant non- } \\
\text { typhoid Salmonella }\end{array}$ & $1-4$ & $2 /-$ \\
\hline $\begin{array}{l}\text { Quinolone resistant non-typhi } \\
\text { Salmonella }\end{array}$ & $0-16$ & $0 /-$ \\
\hline $\begin{array}{l}\text { Ceftazidime-resistant } \\
\text { Pseudomonas aeruginosa }\end{array}$ & $4-21$ & $13 / 10$ \\
\hline $\begin{array}{l}\text { Imipenem-resistant } P \text {. aerugi- } \\
\text { nosa }\end{array}$ & $3-16$ & $14 / 10$ \\
\hline $\begin{array}{l}\text { Ciprofloxacin-resistant } P \text {. } \\
\text { aeruginosa }\end{array}$ & $10-36$ & $15 / 10$ \\
\hline $\begin{array}{l}\text { Imipenem-resistant Acineto- } \\
\text { bacter baumannii }\end{array}$ & $0-19$ & $19 / 16$ \\
\hline $\begin{array}{l}\text { Ciprofloxacin-resistant } A . \text { bau- } \\
\text { mannii }\end{array}$ & $54-74$ & $54 / 42$ \\
\hline
\end{tabular}

\section{VRE and Glycopeptide-Resistant Staphylococci}

The first clinical isolate of Van-A-phenotype VRE (E. faecalis) was found in 1995 (19). Since then, isolation of VRE remains rare and accounts for $<3 \%$ of all clinical isolates of enterococci (20,21). The proportion of Enterococcus hospital isolates resistant to vancomycin in Taiwan is low compared with those in North America and Europe (22), a finding that needs further investigation. However, an increase in VRE 
isolation associated with the continuous widespread use of glycopeptides in a Taiwanese university hospital was observed (23). Furthermore, interhospital and nosocomial spread of some VRE clones, particularly one vanB2 E. faecium clone, or long-term persistence of multiple clones in hospitalized patients still exists $(21,24)$. Although avoparcin has been approved for veterinary use since 1977 , this agent has been banned in the farming industry since 2000 (24). Glycopeptide resistance has been found in some isolates of coagulase-negative staphylococci, particularly in $S$. simulans and $S$. warneri (25).

\section{Macrolide-Resistant Streptococci}

Under the increasing and highly selective pressure of macrolide usage in Taiwan, the prevalence of macrolide resistance and distribution of M-phenotype (mef gene-positive) among macrolide-resistant isolates vary among different streptococcal species (Figure) (26-31). More than $90 \%$ of the S. pneumoniae isolates were resistant to macrolides, and approximately two thirds exhibited high-level resistance $\left(\mathrm{MLS}_{\mathrm{B}}\right.$ phenotype-erm

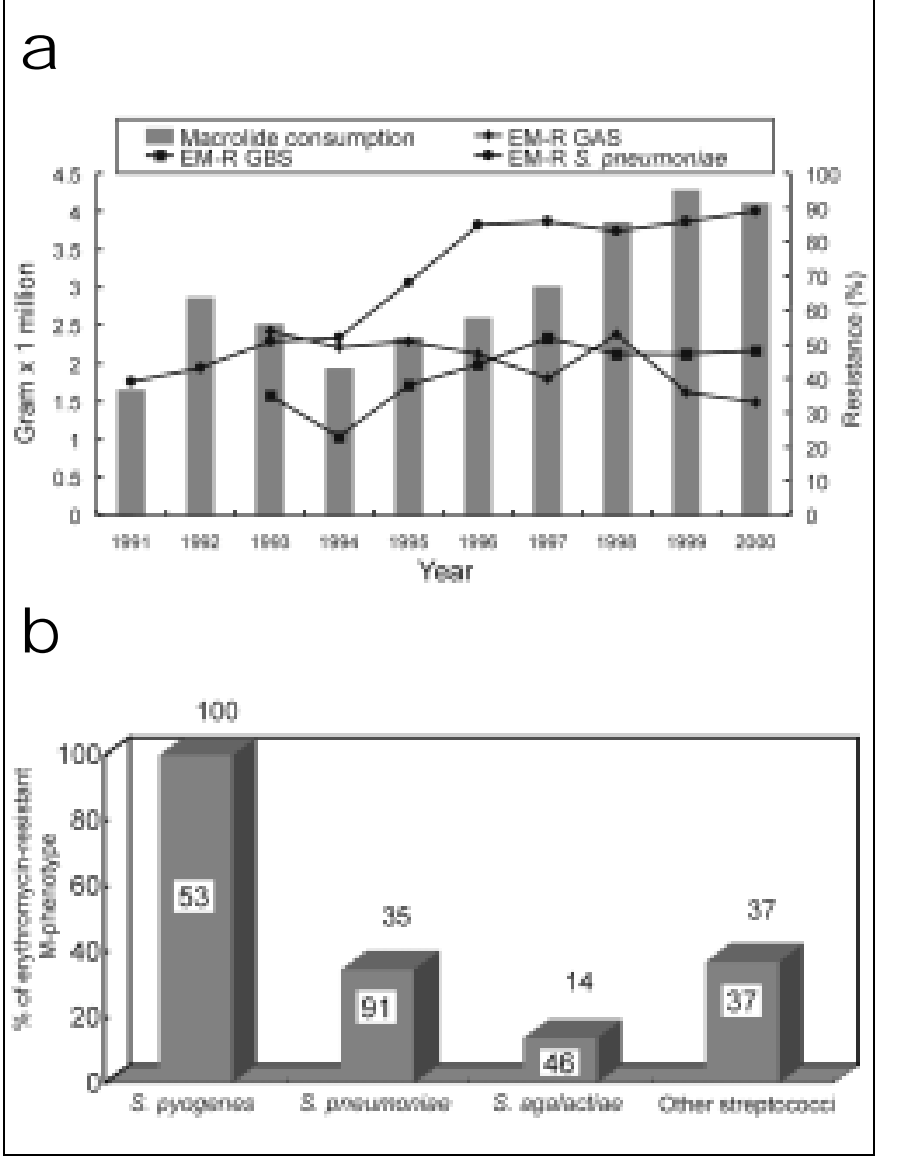

Figure. A, Macrolides consumption (grams x 1,000,000) in Taiwan and the trends of erythromycin-resistant group A Streptococcus (EM-R GAS), group B Streptococcus (EM-R GBS), and S. pneumoniae in National Taiwan University Hospital from 1991 to 2000. Macrolides include intravenous and oral forms of erythromycin and oral forms of clarithromycin, roxithromycin, and azithromycin. B,. Distribution of erythromycin-resistant M-phenotype among isolates of streptococci. Other streptococci include Groups C, F, and G, and viridans group streptococci. Number in each bar indicates the percentage of erythromycin-resistant isolates. Number above each bar indicates the percentage of M-phenotype among erythromycin-resistant isolates. gene-positive) (29). However, macrolide resistance accounted for $50 \%$ to $60 \%$ of all clinical isolates of S. pyogenes, and a stepwise increase of proportion of $\mathrm{M}$ phenotype was clearly demonstrated (29).

\section{Streptogramin-Resistant Gram-Positive Cocci}

Quinupristin-dalfopristin is not available for clinical use in Taiwan; nevertheless, the incidence of resistance to this agent was high $(51 \%)$ in vancomycin-resistant E. faecium (25). Three resistant $E$. faecium isolates were recovered from animal sources (pigs) in Taiwan. Restricted use of virginiamycin, which has been widely used in animal feed for $>20$ years in this country, might be required to alleviate quinupristin-dalfopristin resistance among bacteria from human sources (25).

\section{Multidrug-Resistant Mycobacterium tuberculosis (MDRTB)}

The prevalence of pulmonary tuberculosis (TB) in adults was $0.65 \%$ in 1993 , and the associated death rate was 6.93 per 100,000 in 1998 (32). The overall incidence of isoniazid-resistant $M$. tuberculosis was $31.5 \%$. The incidence of primary resistance (isolates from patients with newly diagnosed TB who had no prior history of anti-TB therapy or from patients whose anti-TB therapy was begun $<2$ weeks) was $12.0 \%$; the incidence of acquired resistance (isolates from patients who had a prior history of anti-TB medication) was $63.0 \%$. The overall incidence of MDRTB was $17.3 \%$ (primary resistance 1.6\%; acquired resistance 46\%) (33). An aggressive intervention program, such as expanded use of directly observed therapy, short course, is ongoing to improve the cure rate of TB and to decrease the resistance rate.

\section{Gram-Negative Bacilli}

\section{H. influenzae and Moraxella catarrhalis}

The annual incidence of invasive $H$. influenzae type b disease in children $<5$ years old was 1.6 to 1.9 per 100,000 population per year before the introduction of conjugated Hib vaccine in 1995 (34). Beta-lactamase production was found in $50 \%$ to $60 \%$ of $\mathrm{H}$. influenzae and in $>95 \%$ of $M$. catarrhalis. BRO-1 isoform accounts for $88 \%$ of all beta-lactamase producers of $M$. catarrhalis $(16,35,36)$. Among amoxicillin-resistant $H$. influenzae isolates, beta-lactamase nonproducers were rare $(<2 \%)$ (16). A continuing upsurge of $H$. influenzae isolates resistant to macrolide $(30 \%)$ and to trimethoprim-sulfamethoxazole $(50 \%)$ during the last decade has become evident $(16,35)$.

\section{Enterobacteriaceae}

The proportion of isolates of $K$. pneumoniae exhibiting the ESBL phenotype has increased progressively from $3.4 \%$ in 1993 to $10.3 \%$ in 1997 in NTUH (37). Approximately one fifth of the ESBL-producing $K$. pneumoniae were also resistant to ciprofloxacin (37). From 1998 through 2000, several reports from different hospitals showed that ESBL production 
accounts for $8 \%$ to $30 \%$ of clinical isolates of $K$. pneumoniae. .Those producing SHV-5 and SHV-12 predominated. In addition, four novel beta-lactamases (CMY-8, SHV-25, SHV-26, and IMP-8) were identified in 2000 in Taiwan (38-42). Among the ESBL-producing E. coli isolates, which accounted for $1.6 \%$ to $6.7 \%$, strains having CTX-M-3 and CMY-M-2 were disseminated in Taiwan $(39,43)$. In Taiwan, the previous belief that characteristically susceptible strains (uniformly susceptible to cephalosporins) of $K$. pneumoniae caused primary liver abscess, an endemic disease entity in patients with diabetes mellitus, has now been disproved because two cephalosporinresistant $K$. pneumoniae strains causing primary liver abscess have been found (44-46).

More than $40 \%$ of clinical isolates of nontyphoid Salmonella species were resistant to multiple antibiotics (ampicillin, chloramphenicol, and trimethoprim-sulfamethoxazole). Resistance to cefotaxime and fluoroquinolones was estimated to be low (1\% to $3 \%)(47)$.

\section{P. aeruginosa, A. baumannii, and Other Bacteria}

$P$. aeruginosa, A. baumannii, and other nonfermentative gram-negative bacilli are usually resistant to various antimicrobial agents. A high proportion of clinical isolates, particularly those recovered from patients in intensive-care units, that are resistant to some last-line agents (ceftazidime, amikacin, ciprofloxacin, and carbapenems) have now been found in Taiwan (3-6,48,49). A small outbreak of infections (three patients) caused by a pan-drug-resistant $P$. aeruginosa (serogroup O:4) clone in an intensive-care burn unit from April 1997 to May 1997 has been identified (3) This clone had been isolated from a patient on the same unit 5 months before the outbreak (3). Among $P$. aeruginosa isolates with reduced susceptibilities to imipenem, VIM-2 and VIM-3 are the predominant metallo-beta-lactamases (50). Furthermore, clonal dissemination of VIM-3-producing $P$. aeruginosa has been found among hospitals in Taiwan (50). Strains of ceftazidimeand ciprofloxacin-resistant $A$. baumannii causing severe community-acquired pneumonia have emerged (49). Infections caused by Chryseobacterium indologenes, a multidrug-resistant nosocomial pathogen, appear to be another emerging problem in Taiwan (5). Isolates of the Chryseobacterium genus have remarkable discrepancies of susceptibility results by the disk-diffusion and dilution method. Vancomycin is not recommended as a drug of choice for treating C. meningosepticum meningitis or other infections caused by Chryseobacterium species because these isolates are highly resistant to vancomycin when the standard agar dilution method is used (4).

Several multidrug-resistant (extended-spectrum cephalosporins, ciprofloxacin, or carbapenem resistance) Aeromonas species have been reported $(51,52)$. A derepressed mutant of $A$. hydrophila, which overexpresses beta-lactamases and shows resistance to extended-spectrum cephalosporins, is used if treatment with cefotaxime for Aeromonas bacteremia fails (52). High prevalence of ciprofloxacin resistance for human isolates of Campylobacter jejuni (52\%) and C. coli (75\%) may be attributable to the widespread use of quinolones in poultry in Taiwan $(53,54)$.

\section{Strategy for Resistance Control in the 21st Century}

By the end of the 20th century, many measures to control resistance problems had been instituted in Taiwan. Antibiotics had been removed from the list of available nonprescription drugs at drugstores. Antibiotic interventions had been implemented in many hospitals, particularly in intensive-care units, to alleviate the high prevalence of resistance among nosocomial pathogens. In 2000, the Council of Agriculture in Taiwan prohibited the use of several antimicrobial agents (such as avoparcin, kanamycin, kitasamycin, lasalocid, spiramycin, salinomycin, and streptomycin), which had been widely used as growth promoters or prophylactic agents in animal husbandry in Taiwan during the past 2 to 3 decades, because they may select for critical forms of resistance in human pathogens in food-producing animals (54). Further research is ongoing to reduce the risk for increasing resistance in human pathogens caused by antibiotic use in animal husbandry. In the new millennium, the Center for Disease Control, Department of Health, in Taiwan, has made control of antimicrobial resistance a major goal. The two main tasks are to restrict use of antibiotics for trivial upper respiratory tract infections and to avoid inappropriate use of antibiotics for surgical prophylaxis.

\section{Acknowledgments}

We thank the members of SMART (Surveillance for Multicenter Antimicrobial Resistance in Taiwan), the Infectious Diseases Society of the Republic of China, and the Society of Laboratory Medicine, the Republic of China. The SMART members from 12 major hospitals in Taiwan include Po-Ren Hsueh, Lee-Jene Teng, Kwen-Tay Luh, Kwok-Woon Yu, Cheng-Yi Liu, Jang-Jih Lu, Feng-Yee Chang, Ting-I Yang, Chun-Ming Lee, Tsu-Lan Wu, Hsieh-Shong Leu, Jainn-Ming Shyr, Yeu-Jun Liu, Jen-Hsieh Wan, Jing-Jou Yang, Wen-Chien Ko, Jiunn-Jong Wu, Yi-Chueh Yang, Yin-Ching Chuang, Chang-Fang Peng, Kao-Pin Hwang, Wen-Kuei Huang, Yung-Ching Liu, and LiShin Wang.

Dr. Hsueh is assistant professor in the Departments of Laboratory Medicine and Internal Medicine at National Taiwan University College of Medicine in Taipei, Taiwan. His research interests include the epidemiology of emerging and nosocomial infections and mechanisms of antimicrobial drug resistance. He is actively involved in developing a national research program for antimicrobial drug resistance (Surveillance for Multicenter Antimicrobial Resistance in Taiwan-SMART).

\section{References}

1. Ho M, McDonald C, Lauderdale TL, Yeh LLL, Chen PC, Shiau YR, et al. Surveillance of antibiotic resistance in Taiwan, 1998. J Microbiol Immunol Infect 1999;32:239-49.

2. Chang SC, Hsieh WC. Current status of bacterial antibiotic resistance in Taiwan. Journal of Infectious Diseases Society of the Republic of China 1996;7:83-8. 
3. Hsueh PR, Teng LJ, Yang PC, Chen YC, Ho SW, Luh KT. Persistence of a multidrug-resistant Pseudomonas aeruginosa clone in an intensive care burn unit. J Clin Microbiol 1998;36:1347-51.

4. Chang JC, Hsueh PR, Wu JJ, Ho SW, Hsieh WC, Luh KT. Antimicrobial susceptibility of flavobacteria as determined by agar dilution and disk diffusion methods. Antimicrob Agents Chemother 1997;41:1301-6.

5. Hsueh PR, Teng LJ, Yang PC, Ho SW, Hsieh WC, Luh KT. Increasing incidence of nosocomial Chryseobacterium indologenes infections in Taiwan. Eur J Clin Microbiol Infect Dis 1997;16:568-74.

6. Shi ZY, Liu PY, Lau YJ, Hu BS, Shir JM. Antimicrobial susceptibility of clinical isolates of Acinetobacter baumannii. Diagn Microbiol Infect Dis 1996;24:81-5.

7. National Committee for Clinical Laboratory Standards. Performance standards for antimicrobial disk susceptibility tests. 6th ed. Approved standard M2-A6. Wayne (PA): The Committee; 1998.

8. Chang SC, Hsu LY, Luh KT, Hsieh WC. Methicillin-resistant Staphylococcus aureus infections. J Formos Med Assoc 1988;87:157-63.

9. Chen ML, Chang SC, Pan HJ, Hsueh PR, Yang LS, Ho SW, et al. Longitudinal analysis of methicillin-resistant Staphylococcus aureus isolates at a teaching hospital in Taiwan. J Formos Med Assoc 1999;98:426-32.

10. Hsueh PR, Chen HM, Lu YC, Wu JJ. Antimicrobial resistance and serotype distribution of Streptococcus pneumoniae strains isolated in southern Taiwan. J Formos Med Assoc 1996;95:29-36.

11. Hsueh PR, Wu JJ, Hsiue TR. Invasive Streptococcus pneumoniae infection associated with rapidly fatal outcome in Taiwan. J Formos Med Assoc 1996;95:364-71.

12. Chiou CC, Liu YC, Huang TS, Hwang WK, Wang JH, Lin HH, et al. Extremely high prevalence of nasopharyngeal carriage of penicillin-resistant Streptococcus pneumoniae among children in Kaohsiung, Taiwan. J Clin Microbiol 1998;36:1933-7.

13. Hsueh PR, Teng LJ, Lee LN, Yang PC, Ho SW, Luh KT. Extremely high incidence of macrolide and trimethoprim-sulfamethoxazole resistance among clinical isolates of Streptococcus pneumoniae in Taiwan. J Clin Microbiol 1999;37:897-901.

14. Hsueh PR, Teng LJ, Lee LN, Yang PC, Ho SW, Luh KT. Dissemination of high-level penicillin-, extended-spectrum cephalosporin-, and erythromycin-resistant Streptococcus pneumoniae clones in Taiwan. J Clin Microbiol 1999;37:221-4.

15. Fung CP, Hu BS, Lee SC, Liu PY, Jang TN, Leu HS, et al. Antimicrobial resistance of Streptococcus pneumoniae isolated in Taiwan. An islandwide surveillance study between 1996 and 1997. J Antimicrob Chemother 2000;45:49-55.

16. Hsueh PR, Liu YC, Shyr JM, Wu TL, Yan JJ, Wu JJ, et al. Multicenter surveillance of antimicrobial resistance of Streptococcus pneumoniae, Haemophilus influenzae, and Moraxella catarrhalis in Taiwan during the 1998-1999 respiratory season. Antimicrob Agents Chemother 2000;44:1342-5.

17. Shi ZY, Enright MC, Wilkinson P, Griffiths D, Spratt BG. Identification of three major clones of multiply antibiotic-resistant Streptococcus pneumoniae in Taiwanese hospitals by multilocus sequence typing. J Clin Microbiol 1998;36:3514-9.

18. Hsueh PR, Teng LJ, Wu TL, Ho SW, Luh KT. First clinical isolate of Streptococcus pneumoniae exhibiting high-level resistance to fluoroquinolones in Taiwan. J Antimicrob Chemother 2001;48:316-7.

19. Ben RJ, Lu JJ, Young TG, Chi WM, Wang CC, Chu ML, et al. Clinical isolation of vancomycin-resistant Enterococcus faecalis in Taiwan. J Formos Med Assoc 1996;95:946-9.

20. Hsueh PR, Wu JJ, Lu JJ, Teng LJ, Luh KT. Antimicrobial susceptibilities of clinical isolates of vancomycin-resistant enterococci in Taiwan. J Formos Med Assoc 1999;98:45-8.

21. Hsueh PR, Teng LJ, Pan HJ, Chen YC, Wang LH, Chang SC, et al. Emergence of vancomycin-resistant enterococci at a university hospital in Taiwan: persistence of multiple species and multiple clones. Infect Control Hosp Epidemiol 1999;20:828-33
22. Hsueh PR, Liu YC, Yang D, Yan JJ, Wu TL, Huang WK, et al. Multicenter surveillance of antimicrobial resistance of major bacterial pathogens in intensive care units in 2000 in Taiwan. Microb Drug Resist 2001;7:345-54.

23. Hsueh PR, Chen ML, Sun CC, Chen WH, Pan HJ, Yang LS, et al. Antimicrbial drug resistance in pathogens causing nosocomial infections at a University Hospital in Tiawan, 1981-1999. Emerg Infect Dis 2002;8:638 .

24. Lu JJ, Perng CL, Ho MF, Chiueh TS, Lee WH. High prevalence of vanB2 vancomycin resistant Enterococcus faecium in Taiwan. J Clin Microbiol 2001;39:2140-5.

25. Luh KT, Hsueh PR, Teng LJ, Pan HJ, Chen YC, Lu JJ, et al. Quinupristindalfopristin resistance among gram-positive bacteria in Taiwan. Antimicrob Agents Chemother 2000;44:3374-80.

26. Hsueh PR, Chen HM, Huang AH, Wu JJ. Decreased activity of erythromycin against Streptococcus pyogenes in Taiwan. Antimicrob Agents Chemother 1995;39:2239-42.

27. Wu JJ, Lin KY, Hsueh PR, Liu JW, Pan HI, Sheu S. High incidence of erythromycin-resistant streptococci in Taiwan. Antimicrob Agents Chemother 1997;41:844-6.

28. Yan JJ, Wu HM, Huang AH, Fu HM, Lee CT, Wu JJ. Prevalence of polyclonal mefA-containing isolates among erythromycin-resistant group A streptococci in southern Taiwan. J Clin Microbiol 2000;38:2475-9.

29. Hsueh PR, Teng LJ, Lee LN, Yang PC, Ho SW, Lue HC, et al. Extremely high proportion and substantial upsurge in incidence of erythromycinresistant M phenotype in Streptococcus pyogenes but not in Streptococcus pneumoniae isolates collected over a 15-year period in Taiwan. Microb Drug Resist. In press 2001.

30. Hsueh PR, Teng LJ, Lee LN, Ho SW, Yang PC, Luh KT. A high incidence of erythromycin resistance among clinical isolates of Streptococcus agalactiae in Taiwan. Antimicrob Agents Chemother 2001;45:3205-8.

31. Teng LJ, Hsueh PR, Chen YC, Ho SW, Luh KT. Antimicrobial susceptibility of viridans group streptococci in Taiwan with an emphasis on the high rates of resistance to penicillin and macrolides in Streptococcus oralis. J Antimicrob Chemother 1998;41:621-7.

32. Department of Health, The Executive Yuan ROC. TB statistics-1998. general health statistics 1998. Taipei:Republic of China; 1998. p. 10-11.

33. Chiang IH, Yu MC, Bai KJ, Wu MP, Hsu CJ, Lin TP, et al. Drug resistance patterns of tuberculosis in Taiwan. J Formos Med Assoc 1998;97:581-3.

34. Chen MK, Wang CC, Chu ML, Pan TM. Prospective surveillance of children with invasive Haemophilus influenzae disease in Taiwan. J Microbiol Immunol Infect 1999;32:257-60.

35. Lin HC, Wang CC, Yu CM, Chu ML. Prevalence of antimicrobial resistance among clinical isolates of Haemophilus influenzae in Taiwan. J Formos Med Assoc 1999;98:319-25.

36. Fung CP, Lee SC, Liu YF, Jang TN, Wong FD, Kuo BI, et al. Beta-lactam resistance and beta-lactamase isoforms of Moraxella catarrhalis isolates in Taiwan. J Formos Med Assoc 1998;97:453-7.

37. Jan IS, Hsueh PR, Teng LJ, Ho SW, Luh KT. Antimicrobial susceptibility testing for Klebsiella pneumoniae isolates resistant to extended-spectrum B-lactam antibiotics. J Formos Med Assoc 1998;97:661-6.

38. Liu PY, Tung JC, Ke SC, Chen SL. Molecular epidemiology of extendedspectrum beta-lactamase-producing Klebsiella pneumoniae isolates in a district hospital in Taiwan. J Clin Microbiol 1998;36:2759-62.

39. Siu LK, Lu PL, Hsueh PR, Lin FM, Chang SC, Luh KT, et al. Bacteremia due to extended-spectrum b-lactamase-producing Escherichia coli and Klebsiella pneumoniae in a pediatric oncology ward: clinical features and identification of different plasmids carrying both SHV-5 and TEM-1 genes. J Clin Microbiol 1999;37:4020-7.

40. Yan JJ, Wu SM, Tsai SH, Wu JJ, Su IJ. Prevalence of SHV-12 among clinical isolates of Klebsiella pneumoniae producing extended-spectrum B-lactamase and identification of a novel AmpC enzyme (CMY-8) in southern Taiwan. Antimicrob Agents Chemother 2000;44:1438-42. 
41. Chang FY, Siu LK, Fung CP, Huang MH, Ho M. Diversity of SHV and TEMb-lactamases in Klebsiella pneumoniae: gene evolution in northern Taiwan and two novel beta-lactamases, SHV-25 and SHV-26. Antimicrob Agents Chemother 2001;45:2407-13.

42. Yan JJ, Ko WC, Wu JJ. Identification of a plasmid encoding SHV-12, TEM-1, and a variant of IMP-2 metallo-beta-lactamase, IMP-8, from a clinical isolate of Klebsiella pneumoniae. Antimicrob Agents Chemother 2001;45:2368-71.

43. Yan JJ, Ko WC, Tsai SH, Wu HM, Lin YT, Wu JJ. Dissemination of CTX-M-3 and CMY-2 beta-lactamases among clinical isolates of Escherichia coli in southern Taiwan. J Clin Microbiol 2000;38:4320-5.

44. Wang JH, Liu YC, Lee SSJ, Yen MY, Chen YS, Wang JH, et al. Primary liver abscess due to Klebsiella pneumoniae in Taiwan. Clin Infect Dis 1998;26:1434-8.

45. Fung CP, Hu BS, Chang FY, Lee SC, Kuo BI, Ho M, et al. A 5-year study of the seroepidemiology of Klebsiella pneumoniae: high prevalence of capsular serotype $\mathrm{K} 1$ in Taiwan and implication for vaccine efficacy. $\mathbf{J}$ Infect Dis 2000;181:2075-9.

46. Hsueh PR, Teng LJ, Chen YC, Luh KT. Primary liver abscess caused by one clone of Klebsiella pneumoniae with two colonial morphotypes and resistotypes. Emerg Infect Dis 2002;8:100-5.

47. Su LH, Chiu CH, Kuo AJ, Chia JH, Sun CF, Leu HS, et al. Secular trends in incidence and antimicrobial resistance among clinical isolates of Salmonella at a university hospital in Taiwan, 1993-1999. Epidemiol Infect. 2001;127:207-13.
48. Liu PYF, Lau YJ, Hu BS, Shyr JM, Shi ZY, Tsai WS, et al. Comparison of susceptibility to extended-spectrum beta-lactam antibiotics and ciprofloxacin among gram-negative bacilli isolated from intensive care units. Diagn Microbiol Infect Dis 1995;22:285-91.

49. Chen ML, Hsueh PR, Lee LN, Yu CJ, Yang PC, Luh KT. Severe community-acquired pneumonia due to Acinetobacter baumannii. Chest 2001; 120: 1072-7.

50. Yan JJ, Hsueh PR, Ko WC, Luh KT, Tsai SH, Wu HM, et al. Metallobeta-lactamases among clinical isolates of Pseudomonas in Taiwan and identification of VIM-3, a novel variant of the VIM-2 enzyme. Antimicrob Agents Chemother 2001;45:2224-8.

51. Ko WC, Yu KW, Liu CY, Huang CT, Leu HS, Chuang YC. Increasing antibiotic resistance in clinical isolates of Aeromonas strains in Taiwan. Antimicrob Agents Chemother 1996;40:1260-2.

52. Ko WC, Wu HM, Chang TC, Yan JJ, Wu JJ. Inducible beta-lactam resistance in Aeromonas hydrophila: therapeutic challenge for antimicrobial therapy. J Clin Microbiol 1998;36:3188-92.

53. Li CC, Chiu CH, Wu JL, Huang YC, Lin TY. Antimicrobial susceptibility of Campylobacter jejuni and coli by using E-Test in Taiwan. Scand $\mathrm{J}$ Infect Dis 1998;30:39-42.

54. McDonald LC, Chen MT, Lauderdale TL, Ho M. The use of antibiotics critical to human medicine in food-producing animals in Taiwan. J Microbiol Immunol Infect 2001;34:97-102.

Address for correspondence: Kwen-Tay Luh, Department of Laboratory Medicine, National Taiwan University Hospital, No. 7 Chung-Shan Road, Taipei 100, Taiwan; fax: 886-2-2322-4263; e-mail: luhkt@ha.mc.ntu.edu.tw

\section{EMERGING \\ Full text free online at www.cdc.gov/eid INFECTIOL
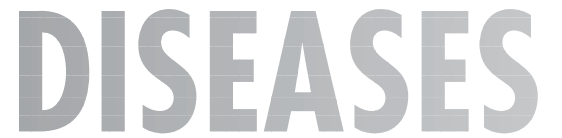

The print journal is available at no charge to public health professionals

YES, I would like to receive Emerging Infectious Diseases.

Please print your name and business address in the box and return by fax to $404-371-5449$ or mail to

$$
\text { EID Editor }
$$

CDC/NCID/MS D61

1600 Clifton Road, NE

Atlanta, GA 30333

Moving? Please give us your new address (in the box) and print the number of your old mailing label here

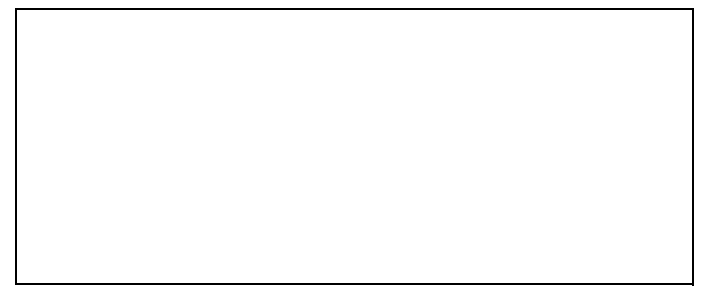

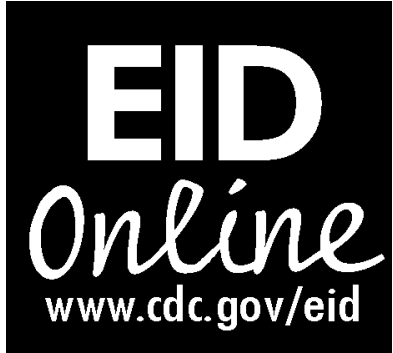

